\title{
Preface
}

\section{Challenge and opportunities in the treatment of gastric cancer}

\author{
Tetsuo Taguchi ${ }^{1}$ and James Bishop ${ }^{2}$ \\ ${ }^{1}$ Japan Society for Cancer Chemotherapy, 505, 1-18-35 Edobori, Nishi-ku, Osaka 550-0002, Japan \\ ${ }^{2}$ Sydney Cancer Center, Sydney, Australia
}

Although changes in diet, refrigeration, and environmental factors have led to a decrease in the incidence of gastric cancer over the last 50 years, this disease, worldwide, remains second only to carcinoma of the lung as a cause of cancer deaths [1-6]. Globally, it is estimated that more than 800000 new cases of gastric cancer are diagnosed each year. This represents around $10 \%$ of all cancers $[1,2]$.

In Japan, where gastric cancer is endemic, early diagnosis through population screening has led to an encouraging 5-year survival rate of $50 \%$, and there are indications that conservative surgery in early disease can produce results as good as more conventional procedures [3,7-9]. In Western Europe, the United States, and Australia, where gastric cancer is frequently diagnosed only when at an advanced stage, 5-year survival rates are more typically in the region of $20 \%-25 \%$, and surgery is frequently seen primarily as a palliative procedure [1,2,5,7-9].

Epidemiologically, gastric cancer remains a common disease; and evidence suggests that the decline seen in its incidence over the past few decades is now clearly slowing. Clinically, gastric cancer remains a devastating condition requiring intensification of our research efforts and the development of an integrated multimodality approach to its more effective management. Designing a research program in this area requires a clear head and a logical line of thought.

Relatively few aspects of the treatment of gastric cancer are agreed upon. This is so even with primary intervention, because the extent to which more radical dissection, as practiced in Japan, is genuinely curative is still debated.

Offpritn requests to: T. Taguchi

Received: April 1, 2002 / Accepted: August 13, 2002
Gastric cancers are considered to show moderate sensitivity to chemotherapy. However, for cases of inoperable gastric cancer, recurrent gastric cancer for which surgery is not indicated, and noncurative resection, it is difficult to achieve complete cure by application of chemotherapy alone. Nevertheless, it is clear that chemotherapy in advanced disease confers significant benefit in median survival and quality of life when compared with best supportive care. This degree of therapeutic efficacy has not been demonstrated with various alternative therapies, including immunotherapy, thermotherapy, etc, which have been used in some parts of the world.

Accordingly, chemotherapy should be considered the first line of treatment for patients with inoperable recurrent gastric cancer and patients undergoing noncurative resection of gastric cancer.

Although the indications of chemotherapy for gastric cancer will be unresectable cases, recurrent cases for which surgery is not indicated, and cases of noncurative resection (curability $\mathrm{C}$ ), in principle, it will also be necessary for the patients to be in comparatively good general health and to have no serious organ failure. In practical terms, the conditions required for the indication of chemotherapy for gastric cancer will be a performance status (PS) of $0-2$, sT4 or a high degree of lymph node metastasis (N3 or more), initial therapy or recurrent cases showing $\mathrm{P} 1, \mathrm{H} 1$, or some other M1, and noncurative resection cases. However, while there is a large body of support currently for the use of cisplatin plus 5-fluorouracil (5-FU), no single regimen has become the treatment standard, and any drug or combination which can consistently achieve a greater than $40 \%-50 \%$ response rate will be an important advance [10-23].

In this context there was considerable interest in the results of the TAX 325 study [24]. In this large randomized phase II trial, the three-drug combination of docetaxel, cisplatin, and continuous infusion 5-FU 
proved superior to the docetaxel/cisplatin doublet in response rate and time to progression. The study was not powered to detect differences in survival. Moreover, it remains for the ongoing phase III comparison of the three drugs above versus cisplatin and 5-FU to provide further evidence on the relative benefit and toxicity profile of the three-drug combination. In Japan, there is considerable interest in the combination of irinotecan with cisplatin, and in monotherapy with the oral fluoropyrimidine S-1 $[18,19]$. A phase III trial will compare the irinotecan/cisplatin doublet with single-agent S-1 and a reference 5-FU arm.

Gastric cancer is a highly heterogeneous disease, the precise anatomical site in which the primary occurs being only the most obvious difference between tumors. It is likely that current chemotherapy protocols for advanced disease are being used to treat cancers of widely varying biology. Determining the molecular characteristics of a given tumor, such as whether it overexpresses Her-2 neu, is being seen as an important step towards the individualization of therapy with current cytotoxic agents and as a precursor of treatment with novel biological agents.

Clinical studies have been carried out with the objective of elucidating the effectiveness of various monotherapy and multidrug chemotherapy regimens in the prevention of recurrence of gastric cancer arising from microscopic residual tumors after curative resection. However, to date there has been little evidence generated which proves a definite life-prolonging effect for any of the tested regimens in the adjuvant setting.

Nevertheless, it has been reported that metaanalysis of the results of a number of randomized controlled clinical studies indicated the existence of a life-prolonging effect with adjuvant therapy [25]. Therefore, it is thought that further clinical studies should be carried out in order to clarify the effects of adjuvant therapy for gastric cancer patients. A large-scale controlled trial in Japan yielded results showing that postoperative chemotherapy is not necessary for $\mathrm{T} 1$ gastric cancer patients, regardless of whether or not there is lymph node metastasis, or for T2 patients without lymph node metastasis. A clinical study is required in gastric cancer patients who undergo curative resection, excluding those with early-stage cancer and T2/N0 patients. However, at present, we are still unable to recommend a specific chemotherapy regimen as a standard therapy. Despite the unsatisfactory nature of current treatments, there is a sense of progress. The findings of the Southwest Oncology Group (SWOG) 9008 study, showing that the combination of chemotherapy with radiotherapy postoperatively improved disease-free and overall survival, has generated renewed interest in adjuvant treatment after several decades barren of positive adjuvant chemotherapy trials [26]. Further, the intro- duction of active new agents has greatly extended the choice of options for chemotherapy in all disease settings. There is a clear justification for new regimens of proven value in advanced disease to be assessed in adjuvant and neoadjuvant roles.

Neoadjuvant chemotherapy is a consolidated therapy which first aims at bringing about shrinkage of tumors, after which the residual primary tumor and/or metastatic lesions are resected. The shortterm efficacy is evaluated on the basis of the response rate and the resection rate, but it goes without saying that the final assessment endpoint is the life-prolonging effect as represented by the survival rate.

There have been a very small number of reports of cases of longterm survival when neoadjuvant chemotherapy was administered to patients who were unable to undergo radical resection of gastric cancer. Early indications (such as an increase in resectability) are promising, but the value of neoadjuvant chemotherapy (possibly combined with radiation) in gastric cancer has still to be demonstrated in large randomized trials. Several European studies are ongoing. In principle, the indication for neoadjuvant chemotherapy of gastric cancer would be patients who have moderately advanced disease and have a possibility of achieving curability B even when treated by surgery alone, but are at high risk of recurrence. The objective of neoadjuvant chemotherapy would be to control micrometastases in these patients. In concrete terms, the conditions for an indication would be cStage II-IIIB, that is, cT3-4, with cN1-3, $\mathrm{P} 0, \mathrm{H} 0$. However, it is also possible to have an indication for patients with highly advanced gastric cancer but the potential to achieve curability B when treated by chemotherapy and surgery. In such patients, neoadjuvant chemotherapy would be carried out with the objective of achieving down-staging prior to surgery.

In the chemotherapy of advanced disease, one approach is clearly to treat with an established firstline regimen, holding newer agents in reserve for second-line use on disease progression. Arguably, a disadvantage of this approach is that active agents are then being used against disease which has become both larger in bulk and more chemoresistant in character.

An alternative is to use more newer single agents and combinations in earlier treatment, possibly using noncross-resistant agents in quick succession in a sequential first-line strategy. Whether this would lead to a higher rate and greater degree of response remains to be demonstrated, but there must be at least the theoretical prospect of achieving a state of minimal residual disease in which the low-toxicity molecularly targeted agents, such as epidermal growth factor receptor (EGFR) and angiogenesis inhibitors, stand a chance of maintaining longterm control. 


\section{References}

1. Gunderson LL, Donohue JH, Burch PA. Stomach. In: Abeloff MD, Armitage JO, Lichter AS, Niederhuber JE, editors. Clinical oncology. New York, NY: Churchill Livingstone; 1995. p 1209-41.

2. Greenlee RT, Murray T, Bolden S, Wingo PA. Cancer statistics 2000. CA Cancer J Clin 2000;50:7-33.

3. Aoki K, Kurihara M, Hayakawa N, Suzuki S, editors. Death rates for malignant neoplasms for selected sites by sex and 5-year age group in 33 countries 1953-57 to 1983-87. Nagoya, Japan: University of Nagoya Coop Press; 1992.

4. Ries LA, Kosary CL, Hankey BF, Miller BA, Edwards BK, editors. SEER Cancer Statistics Review 1973-1995. Bethesda, MD: National Cancer Institute; 1998.

5. South Australian Cancer Registry. Epidemiology of cancer in South Australia. Incidence, mortality and survival, 1977-1992. Incidence and mortality, 1992. Adelaide: Lutheran Publishing; 1993. p 11-22.

6. Karpeh MS, Kelsen DP, Tepper JE. Cancer of the stomach. In: DeVita VT, Hellman S, Rosenberg SA, editors. Cancer: principles and practice of oncology. Philadelphia: Lippincott, Williams and Wilkins; 1993. p 1092-1122.

7. Parkin DM, Whelan SL, Ferlay J, Raymond L, Young J, editors. Cancer incidence in five continents, volume VII. IARC Scientific Publications No. 143. Lyon: International Agency for Research on Cancer; 1997.

8. Nomura A. Stomach cancer. In: Schottenfeld D, Fraumeni JF, editors. Cancer epidemiology and prevention. 2nd Ed. New York: Oxford University Press; 1996. p 707-24.

9. Hisamuchi S, Fukao P, Sugawara N, et al. Evaluation of mass screening programme for stomach cancer in Japan. In: Miller AB, Chamberlain J, Day NE, Hakama M, Prorok PC, editors. Cancer screening. Cambridge: Cambridge University Press; 1991. p 35772.

10. Wils JA, Bleiberg H, Dalesio O, et al. An EORTC gastrointestinal evaluation of the combination of sequential methotrexate, and 5-fluorouracil combined with adriamycin, in advanced measurable gastric cancer. J Clin Oncol 1986;4:1799-803.

11. Wils JA, Klein HO, Wagener DJT, Breiberg H, Reis H, Korsten $\mathrm{F}$, et al. Sequential high-dose methotrexate and fluorouracil combined with doxorubicin: a step ahead in the treatment of advanced gastric cancer: a trial of the European Organization for Research and Treatment of Cancer Gastrointestinal Tract Cooperative Group. J Clin Oncol 1991;9:827-31.

12. Kelsen D, Atiq OT, Saltz L, Niedzwiecki D, Ginn D, Chapman D, et al. FAMTX versus etoposide, doxorubicin, and cisplatin: a random assignment trial in gastric cancer. J Clin Oncol 1992;10:541-8.

13. Webb A, Cunningham D, Scarffe JH, Harper P, Norman A, Joffe JK, et al. Randomized trial comparing epirubicin, cisplatin and fluorouracil versus fluorouracil, doxorubicin, and methotrexate in advanced esophagogastric cancer. J Clin Oncol 1997;15:261-7.

14. Cascinu S, Labianca R, Allesandroni P, Marcellini M, Silva RR, Pancera G, et al. Intensive weekly chemotherapy for advanced gastric cancer using fluorouracil, cisplatin, epi-doxorubicin, 6S- leucovorin, glutathione, and filgrastim: a report from the Italian Group for the Study of Digestive Tract Cancer. J Clin Oncol 1997;15:3313-9.

15. Bokemeyer C, Hartmann JT, Lampe CS, Clemens MR, Quietzsch D, Forkmann L, et al. Paclitaxel and weekly 24-hour infusion of 5-fluorouracil/folinic acid in advanced gastric cancer. Semin Oncol 1997;24(6 Suppl 19):S19-96-S19-100.

16. Kim YH, Shin SW, Kim BS, Kim JH, Kim JG, Mok YJ, et al. Paclitaxel, 5-fluorouracil, and cisplatin combination chemotherapy for the treatment of advanced gastric carcinoma. Cancer 1999;85:295-301.

17. Murad AM, Petroianu A, Guimaraes RC, Aragao BC, Cabral LO, Scalabbrini-Neto AO. Phase II trial of the combination of paclitaxel and 5-fluorouracil in the treatment of advanced gastric cancer: a novel, safe, and effective regimen. Am J Clin Oncol 1999;22:580-6.

18. Shirao K, Shimada Y, Kondo H, Saito D, Yamao T, Ono H, et al. Phase I-II study of irinotecan hydrochloride combined with cisplatin in patients with advanced gastric cancer. J Clin Oncol 1997; 15:921-7.

19. Sato A, Kurihara M, Matsukawa M, Shimada K, Yamazaki T, Nakamachi M, Koda T. Preliminary study of fortnightly irinotecan hydrochloride plus cisplatin therapy in patients with advanced gastric and colorectal cancer. Cancer Chemother Pharmacol 2001;47:380-4

20. Ajani JA, Baker J, Pisters PW, Ho L, Feig B, Mansfield PF. Irinotecan plus cisplatin in advanced gastric or gastroesophageal junction carcinoma. Oncology (Huntingt) (3 Suppl 5) 2001;15:524.

21. Pozzo C, Bugat R, Peschel C, Corbunova V, Valvera V, Zaluski J, et al. Irinotecan in combination with CDDP or 5-FU and folinic acid is active in patients with advanced gastric or gastro-oesophageal junction adenocarcinoma: final results of a randomised phase II study (abstract). Proc Am Soc Clin Oncol 2001;20:531.

22. Grau JJ, Martín M, Gascón P, Pera M, Graupera J, Ballcells M, et al. Phase II study of irinotecan (CPT-11) and mitomycin C (MMC) combination in patients with advanced gastric cancer (ENG). Preliminary results (abstract). Proc Am Soc Clin Oncol 2001;20:2284

23. Findlay PN, Ackland S, Gebski V, Yuen J, Boyer M, Walpole E, et al. Phase II study of irinotecan, leucovorin and 5FU (ILF) in advanced gastric cancer (abstract). Proc Am Soc Clin Oncol 2001;20:655.

24. Ajani JA, Fodor M, Van Cutsem E, Tjulandin S, Moiseyenko V, Cabral F, et al. Multinational randomized phase II trial of docetaxel (T) and cisplatin (C) with or without 5-fluorouracil (FU) in patients (pts) with advanced gastric or GE junction adenocarcinoma (AGC-AGEJC) (abstract). Proc Am Soc Clin Oncol 2000;19:957.

25. Earle CC, Maroun JA. Adjuvant chemotherapy after curative resection for gastric cancer in non-Asian patients: revisiting a meta-analysis of randomized trials. Eur J Cancer 1999;35:1059-64.

26. Macdonald JS, Smalley SR, Benedetti J, Hundahl SA, Estes NC, Stemmermann GN, et al. Chemotherapy after surgery compared with surgery alone for adenocarcinoma of the stomach or gastroesophageal junction. New Engl J Med 2001;345:725-30. 